\section{- to: Bergman RN (2000) Non-esterified fatty acids and the liver: why is insulin secreted into the portal vein? Diabetologia 43: 946-952}

To the Editor: Bergman argues in his article [1] that the reduction in hepatic glucose output does not result from insulin secreted by beta cells into the portal vein. He hypothezises that NEFA are the primary regulators of hepatic glucose output (HGO), with insulin only having an indirect effect. But this view, and the strong correlation reported between hepatic glucose output and NEFA, are not documented in this paper. His interpretation of the results on conscious fasted normal dogs does not take into account that insulin's counterregulatory action could cause the delay in the reduction of hepatic glucose output. The reduction of hepatic glucose output depends on the quantity of insulin (which is not given in the article) administered into a peripheral or into the portal vein as well as on nutritional and diabetic states. Bergman's results are irreconcilable with the direct effect of insulin, well documented in 42year old papers on the reduction of hepatic glucose output [2-6]. These studies report the release of glucose and urea by isolated insulin-perfused liver in cases where changes in NEFA were ruled out. In addition, his findings contradict those of at least 6 important papers published between 1958-1966 (not cited by Bergman, as is the tendency of more recent studies) and my own results $[7,8,9]$ on diabetic and control rats, anaesthetised with pentobarbital, which showed that the hepaportal glucose difference (H-P) was reduced 8-10 min after the injection with $0.1 \mathrm{U} / \mathrm{kg}$ of insulin and later reversed from positive to negative. The effect of lower doses of insulin injected into a peripheral vein on glucose utilisation were mainly peripheral - on adipose and muscular tissue. Higher doses given intravenously could, however, suppress hepatic glucose output by reaching the liver via the hepatic artery. The application of causal logic and of the adaptive and non-adaptive teleological principle make Bergman's question "why?" a good starting point for explaining these facts. My explanation is that insulin is secreted into the portal vein and liver pulsatilly in order to restrain HGO. Insulin is secreted in larger amounts after ingestion of glucose or carbohydrates to ensure the direct deposition of glycogen from absorbed glucose and proteosynthesis from absorbed aminoacids, while triglycerides circumventing the liver are deposited in the adipose tissue. Although NEFA could have a secondary influence on insulin sensitivity, insulin is the main factor involved in reducing HGO both in diabetic animals and diabetic human beings. Finally, I am surprised to see the distorted anatomy depicted in Fig 1, 2A and 2B. The portal vein enters the liver from the caudal, concave face and the $\mathrm{HGO}$ and non-retained insulin flow from the hepatic veins on the cranial, convex face!

R. Korec MD, ScD

\section{References}

1. Bergman RN (2000) Non-esterified fatty acids and the liver: why is insulin secreted into the portal vein? Diabetologia 43: 946-952

2. Madison LL, Unger RH (1958) The physiologic significance of the secretion of endogenous insulin into the portal circulation. I. Comparison of the effects of glucagon-free insulin administration via the portal vein and via a peripheral vein. J Clin Invest 37: 631-638

3. Madison LL, Combes B, Strickland W et al. (1959) Evidence for a direct effect of insulin on hepatic glucose output. Metabolism 8: 469-471

4. Mortimore G (1963) Effect of insulin on release of glucose and urea by isolated perfused rat liver. Am J Physiol 204: 699-700

5. V. Holt, L, Nolte I, v.Holt C (1959) Wirkung der portalen Infusion von Insulin auf den Einbau von U-C14-Glucose in Leber-und Muskelglykogen. Endokrinologie 37: $36-42$

6. Söling HD, Koschel R, Drägert et al. (1966) Die Wirkung von insulin auf den Stoffwechsel der isolierten perfundierten Leber normaler und alloxandiabetischer Ratten. Diabetologia 2: 30-31, 32-44

7. Korec R (1960) The effect of insulin infused into the portal and systemic vein in rats. Cs Fysiol 9: 433-434 (In Slovak)

8. Korec R (1961) Ein Beitrag zu der periphren und hepatalen Wirkung Insulins. 4 e Congrès Feder. Internat. Diabète. Vol. 1: 589-590. Ed Méd et Hygiène, Genève

9. Korec R (1991) Experimental and spontaneous Diabetes mellitus in the Rat and Mouse. Monograph in English. Univ. Edit. Center, Kosice, pp 60-61

Corresponding author: Prof. Rudolf Korec, MD, ScD, Experimental Pathologist and Diabetologist, Pokroku 4, 04011 Kosice, Slovakia

\section{Observations}

\section{Munchausen's syndrome manifesting as factitious hypoglycaemia}

To the Editor: Factitious hypoglycaemia is a specific type of Munchausen's syndrome the diagnosis of which requires multiple expensive investigations. The incidence of this particular disorder is now equal to that of insulinoma.

Munchausen's syndrome is an unusual syndrome first reported by Asher in 1951 [1]. Sufferers describe past histories that are dramatic and believable but untrue and they present with an 'acute illness' [1]. After numerous painful and unnec- essary investigations [2] or operations, the many falsehoods in a patient's history can be discovered. At this point a patient might consult a different doctor or hospital, sometimes with a different name [1].

Factitious hypoglycaemia is a specific type of Munchausen's syndrome [3] and is almost impossible to differentiate from an insulinoma at initial presentation. Reports have stated that the incidence of factitious hypoglycaemia is almost equal to that of insulinoma, [4] providing many diagnostic problems. The diagnosis of factitious hypoglycaemia is made when a patient is known to have surreptitiously self-administered insulin or oral hypoglycaemic agents to induce a hypoglycaemic attack [2].

The first diagnostic step in any patient suspected to have hypoglycaemia is to confirm by laboratory assay that the plasma glucose concentration is less than $2.2 \mathrm{mmol} / \mathrm{l}$ 